\title{
Pedagogias da Imprensa Negra: entre fragmentos biográficos e fotogravuras
}

\section{Pedagogies of the Black Press: Between biographical fragments and photogravures}

\author{
Maria Angélica Zubaran ${ }^{1}$
}

\begin{abstract}
RESUMO
Este artigo investiga as pedagogias do jornal de Imprensa Negra $O$ Exemplo, nas primeiras décadas do século XX. O objetivo central é analisar os fragmentos biográficos e as fotogravuras que os jornalistas do jornal $O$ Exemplo produziram e fizeram circular sobre afrodescendentes. Inicialmente, apresento o jornal $O$ Exemplo e discuto a positividade pedagógica da mídia e a noção de pedagogia. Em segundo lugar, aproprio-me dos argumentos de Stuart Hall, para analisar as fotogravuras de afrodescendentes veiculadas pelo jornal e também abordo diferentes perspectivas analíticas sobre o uso da fotografia. Finalmente, procuro demonstrar que tanto os fragmentos biográficos quanto as fotogravuras do jornal $O$ Exemplo foram estrategicamente produzidos para disseminar pedagogias e construir modelos de negros com os quais os afrodescendentes poderiam se identificar e construir sua autoestima.

Palavras-chave: Imprensa Negra; fragmentos biográficos; fotogravuras; pedagogias.
\end{abstract}

\begin{abstract}
This article investigates the pedagogies of the Black Press newspaper $O$ Exemplo in the first decades of the twentieth century. The main objective is to analyze the biographical fragments and photogravures that the newspaper's journalists produced and circulated on Afro-descendants. Initially, I briefly present the newspaper and discuss the pedagogical positivity of the media and the notion of pedagogy. Secondly, I rely on Stuart Hall's arguments on black photographs in the media to analyze the Afro-descendants' photogravures in
\end{abstract}

DOI: $10.1590 / 0104-4060.43561$

1 Universidade Luterana do Brasil. Canoas, Rio Grande do Sul, Brasil. Rua Farroupilha, ${ }^{\circ}$ 8001. São José. CEP: 92425-900.E-mail: angelicazubaran@yahoo.com.br 
that journal and I also approach different analytical perspectives on the use of photography. Finally, I try to show that both the biographical fragments and the newspaper photogravures were strategically produced to disseminate pedagogies and to construct black models with which Afro-descendants could identify and build their self-esteem.

Keywords: Black Press; biographical fragments; photogravures; pedagogies.

Este estudo sobre as pedagogias da Imprensa Negra tem como objetivo analisar fragmentos biográficos e fotogravuras ${ }^{2}$ de afrodescendentes vestindo togas de formatura, veiculados no jornal de Imprensa Negra $O$ Exemplo, nas primeiras décadas do século XX. A partir da abordagem teórica dos Estudos Culturais, pretendo demonstrar que tanto os fragmentos biográficos quanto as fotogravuras foram estrategicamente produzidos no jornal $O$ Exemplo para disseminar pedagogias e construir modelos de negros com os quais os afrodescendentes poderiam se identificar e construir sua autoestima nas primeiras décadas do século XX.

O jornal $O$ Exemplo, selecionado para esta análise, é um periódico da chamada Imprensa Negra, produzido por afro-rio-grandenses na cidade de Porto Alegre e que circulou no período entre 1892 e 1930. A trajetória do jornal foi marcada por quatro fases relativas aos diferentes períodos de sua publicação: 1892/97, 1902/05, 1908/11 e 1916/30. Neste estudo, meu foco será no período que corresponde à última fase de existência do jornal, entre 1916 e 1930. O jornal foi fundado por um grupo de jovens negros, "moços esperançosos e ávidos de justiça", que costumavam reunir-se em uma barbearia, o Salão Calixto, situado à Rua dos Andradas n ${ }^{\circ} 247$, no centro da cidade de Porto Alegre. A maioria dos diretores e redatores do jornal $O$ Exemplo tinha como principal fonte de renda o emprego público federal. Havia entre eles um núcleo de profissionais liberais, advogados, como Arthur Ferreira de Andrade, Dário de Bittencourt e José da Silva Dias, acadêmicos de direito e de medicina, como os irmãos João Baptista da Silva Junior e Felippe Baptista da Silva, e os médicos Dr. Alcides Feijó das Chagas Carvalho e Dr. Arnaldo Dutra. Além deles, havia alguns operários, que trabalhavam nas fábricas da capital gaúcha. Em geral, eles se declaravam católicos e republicanos e pertenciam e circulavam em diferentes espaços de uma ampla rede social que incluía associações culturais, religiosas, musicais, esportivas, dramáticas e carnavalescas. Como mostraram Felipe Bohrer (2014) e Isabel

2 Fotogravura é o processo utilizado para reprodução de fotografias em jornais, introduzido na imprensa em 1880. Esse processo de gravação fotográfica em chapas de zinco é chamado de autotipia, clichê ou fotogravura. (AZEVEDO, 2009). 
Silveira dos Santos (2015), entre os afrodescendentes que participaram como colaboradores do jornal $O$ Exemplo, em Porto Alegre, nas primeiras décadas do século $\mathrm{XX}$, muitos se dedicaram às artes, principalmente à música e ao teatro, destacando-se grande número de músicos, maestros, atores e atrizes negros.

$\mathrm{Na}$ perspectiva teórica dos Estudos Culturais, compartilho com Rosa B. Fischer (2002), Durval Muniz de Albuquerque (2008) e Marisa V. Costa (2012), a ideia de que a mídia não se constitui apenas como uma fonte básica de informação, mas que se trata de um lugar poderoso no que diz respeito à produção e à circulação de valores, concepções e representações que contribuem na construção de subjetividades e identidades. De acordo com Fischer, "[...] o próprio sentido do que seja educar-se amplia-se" com a contribuição inegável dos meios de comunicação. (FISCHER, 2002, p. 153). Também Durval Muniz de Albuquerque (2008), ao discutir o processo de educação que se passa fora do recinto da escola, chamou atenção para a multiplicidade de pedagogias que operam no cotidiano e argumentou que "[...] a mídia e os meios de comunicação de massa são pedagogos onipresentes orientando nossas vidas e nossas mortes". (ALBUQUERQUE, 2008, p. 2). Nesta direção, Costa (2012) aponta que as revistas são produtivas e constroem relatos interessados que operam sobre nossas vidas, orientando nossas escolhas, apontando-nos caminhos, construindo significados sobre o mundo, sobre as identidades e a sociedade em que vivemos. Neste sentido, considera-se que a mídia impressa, mais especificamente, o jornal O Exemplo, por meio de múltiplos recursos, produziu e disseminou valores e modos de ser e estar no mundo e exerceu um papel pedagógico significativo na construção de subjetividades e identidades negras.

Proponho, ainda, que a Imprensa Negra ao nomear e visibilizar o protagonismo negro na sociedade brasileira da época, desestabilizou o silêncio e o ocultamento sobre os intelectuais negros e as suas contribuições à cultura nacional. Conforme sugeriu Stuart Hall (2003), nestes momentos, "os traços africanos", escravizados e colonizados, que sempre foram não ditos, subterrâneos e subversivos, se tornavam visíveis. Portanto, as narrativas verbais e imagéticas veiculadas no jornal $O$ Exemplo, ao encenarem publicamente o "direito de significar" para os afrodescendentes, se constituíram como um espaço de transgressão.

Na direção apontada por Leonor Arfuch (2010), falar de fragmentos biográficos não remete apenas a um arrolar de acontecimentos numa ordem sequencial daquilo que seria o registro de uma vida humana, mas opera na Imprensa Negra como um arquivo de modelos de histórias individuais articulados a um projeto pedagógico que lhes dá sentido e que diz respeito ao aperfeiçoamento moral e intelectual dos "homens de cor". Já na primeira edição do jornal $O$ Exemplo pode-se ler: "O nosso programa é simples e podemos exará-lo em duas palavras: a defesa de nossa classe e o aperfeiçoamento de nossos medíocres conheci- 
mentos". (O Exemplo, 11 dez. 1892, p. 1). O potencial pedagógico e a vontade de formar afrodescendentes por meio de modelos de negros se expressava de forma explícita no editorial do jornal O Exemplo sob o título "o preconceito e a nacionalidade" em que o redator afirmava:

Com efeito, em que mais $O$ Exemplo pode concorrer para o aperfeiçoamento de um indivíduo, de uma sociedade? Onde buscar mais fartos ensinamentos que nos exemplos dos que são os nossos mentores? Os deste jornal sabem que mais vale um só exemplo do que cem colunas de áridas definições. (O Exemplo, 03 jul. 1927, p. 1).

Inicialmente, inspiro-me nas reflexões de Camozzato e Costa (2013) para pensar as pedagogias disseminadas pelo jornal $O$ Exemplo. Para as autoras, “[...] a pedagogia se relaciona, assim, com o modo de conduzir os sujeitos, de operar sobre eles para obter determinadas ações". (CAMOZZATO; COSTA, 2013, p. 26), constituindo-se numa vontade de produzir determinadas subjetividades e identidades. Aproprio-me do argumento das autoras, de que nas décadas finais do século XX, uma multiplicidade de pedagogias adquire proeminência e da ideia de que está em funcionamento o que chamam de "vontade de pedagogias", para destacar que já no início do século XX pode-se apontar na Imprensa Negra uma multiplicidade de pedagogias em atividade, assim como uma vontade de pedagogia, que se manifesta nos esforços contínuos dos jornalistas afrodescendentes para conduzir e "dar forma" aos sujeitos da comunidade negra porto-alegrense e de atuar em vários âmbitos de suas vidas. Sublinho também, na direção apontada pelas autoras, a maleabilidade da pedagogia frente às contingências de cada tempo/espaço. E, no contexto das décadas que se seguiram ao pós-abolição, em que o abalo sobre as relações sociais e de trabalho foi vivenciado com grande dificuldade pelos afrodescendentes, aponto para a disseminação de múltiplas pedagogias na Imprensa Negra para conduzir os sujeitos negros nas suas aspirações de ascensão social.

Em segundo lugar, para análise das fotogravuras, me aproprio das contribuições de Stuart Hall (1997), em seu estudo de imagens de negros na mídia, quando o autor destaca que as imagens visuais são poderosas e apresentam significados potenciais e ambíguos e não têm um significado único, verdadeiro e definitivo, uma vez que seus significados "flutuam". Neste sentido, a pergunta seria: que significados os jornalistas afrodescendentes do jornal $O$ Exemplo pretenderam privilegiar com a produção de imagens de negros vestindo togas? Conforme aponta Hall (1997), é claro que não há uma resposta "certa" nem 
"errada" para esta pergunta. A imagem tem vários significados, todos eles plausíveis. No entanto, uma possível resposta, no nível denotativo, de significação literal, seria de que as imagens de afrodescendentes de toga teriam a ver com a construção das identidades étnico-raciais desse grupo no início do século XX. Um grupo que frequentemente era representado nas notícias como "vítimas" ou "perdedores" e que nessas imagens afirmava-se como vencedor, em um momento de vitória, da conquista de um diploma.

Nesta direção, Petrônio Domingues (2013) refere que no pós-abolição o negro "descobriu" cada vez mais a importância da educação e o valor dos diplomas. "Não somente os descobriu como resolveu agenciá-los por iniciativas próprias, sem depender da ação do Estado". (DOMINGUES, 2013, p. 295). Na mesma direção, Petronilha Beatriz Gonçalves e Silva (2005) destaca que para os negros a educação não é somente um caminho de realização individual, mas que a formatura de cada estudante negro reverbera em toda a comunidade negra, que se realiza e se fortalece, daí a importância social atribuída aos diplomas conquistados pelos afrodescendentes em um cenário marcado pelas desigualdades étnico-raciais e pelas dificuldades de acesso da população negra à educação formal.

\section{Fotogravuras de afrodescendentes na Imprensa Negra de Porto Alegre}

Ana Maria Mauad (2008) e Machado Júnior (2011), em seus estudos sobre os usos da fotografia, apontaram que a recorrência de temas nas imagens fotográficas sugere a criação de tipologias temáticas. Neste caso particular, os redatores do jornal $O$ Exemplo, para potencializar o protagonismo dos "homens de cor", os representaram de forma recorrente vestindo a toga da formatura, produzindo uma tipologia de imagens que podemos chamar de "fotografias de formatura". Fotografias de formatura foram divulgadas publicamente em revistas e jornais, articuladas às transformações relativas ao processo de urbanização que se delineava na década de 1920, como símbolo de distinção de uma parcela de indivíduos letrados da população brasileira. Nesta direção, Philippe Dubois (1994) aponta que a fotografia é um ato culturalmente codificado, uma imagem de natureza indiciária e simbólica. Neste sentido, na fotografia de formatura, a toga e o capelo, de uso obrigatório nas cerimônias de colação de grau nas universidades, são símbolos que contribuem tanto para construir uma imagem de ascensão social e cultural desses indivíduos, quanto para reverter 
os significados associados aos preconceitos ainda prevalentes na sociedade daquela época. Também Peter Burke (2004) argumenta que o retrato é uma "apresentação do eu", um processo de autorrepresentação, uma performance, na qual os acessórios representados junto aos modelos geralmente reforçam as suas autorrepresentações.

Conforme Fabiana Bruno (2012), a fotografia de formatura também pode ser compreendida como uma imagem-memória, conectada ao universo da "fotografia de família", no contexto da vida privada e das relações familiares. No entanto, nesta pesquisa, o interesse pelas fotografias de formatura relaciona-se à sua circulação na mídia impressa e ao seu potencial pedagógico na educação de afrodescendentes. Nesta direção, estudos como os de Nalida Marinho (2014), Machado Júnior (2015) e Zita Possamai (2015) têm destacado o uso da fotografia como fonte e objeto potencial de investigação na história da educação, permitindo articular múltiplos diálogos entre fotografia, educação e pedagogias. Neste estudo, privilegio os significados conotativos das fotografias de formatura de afrodescendentes, que dizem respeito ao seu potencial pedagógico, como produtoras de modelos de negros para a comunidade afrodescendente de Porto Alegre.

De acordo com Beatriz Marocco (2009), fotógrafos e fotojornalistas produziram imagens fotográficas de negros em Porto Alegre entre meados do século XIX e as primeiras décadas do século XX. A autora aponta que, para os fotógrafos, os jornais eram uma mídia para publicidade, que auxiliava a popularização dos seus estúdios. Marocco (2009) destaca a presença de três fotógrafos e de seus estúdios nesta época, em Porto Alegre: os Irmãos Ferrari, Calegari e Lunara. A autora refere, ainda, que as publicidades de Calegari eram frequentes nos jornais e revistas do início do século, assim como sua colaboração ilustrando capas de revistas e fazendo um inventário imagético das figuras de destaque da sociedade porto-alegrense. De acordo com Marocco (2009), as primeiras décadas do século XX marcaram o nascimento do fotojornalismo no Brasil. Vale destacar que, nesta época, os jornais buscaram na fotogravura uma forma de adentrar na modernidade e atrair leitores. Marocco (2009) aponta, ainda, que em vários jornais de Porto Alegre, nas primeiras décadas do século XX, os negros eram representados de forma negativa e associados à criminalidade e à contravenção, assim como os bairros e ruas onde moravam eram frequentemente descritos como "antros" e "lugar de vagabundos e bandidos". Este era o caso do jornal Gazeta da Tarde, A Gazetinha, O Independente, entre outros. Neste sentido, a divulgação de retratos de afrodescendentes vestindo a toga de formatura no jornal $O$ Exemplo constitui-se também como uma estratégia pedagógica de reversão de significados de representações estereotipadas e racistas que eram frequentemente publicadas em outros periódicos locais. 
As fotogravuras de afrodescendentes no jornal $O$ Exemplo não referem a autoria do fotógrafo. No entanto, localizamos no jornal anúncios do estúdio Ferrari e do atelier fotográfico Barbeitos e Irmãos, localizado na Rua Avay, $\mathrm{n}^{\mathrm{o}}$ 64, que como sugere o anúncio era especializado em retratos. Esses dois fotógrafos foram, provavelmente, os responsáveis pelos retratos de afrodescendentes veiculados no jornal. Também a litografia Minck e Robles, como sugere a errata reproduzida abaixo, era uma alternativa para as ilustrações do jornal $O$ Exemplo.

FIGURA 1 - ANÚNCIO

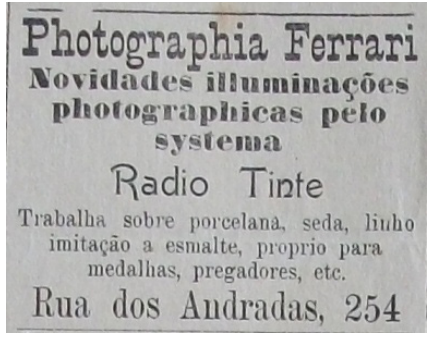

FONTE: O Exemplo, $04 \mathrm{dez} .1904$, p. 4.
FIGURA 2 - ANÚNCIO

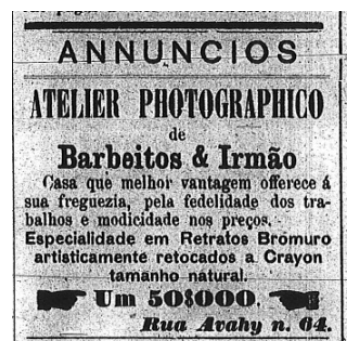

FONTE: O Exemplo, 13 maio 1904, p. 3.

FIGURA 3 - ANÚNCIO

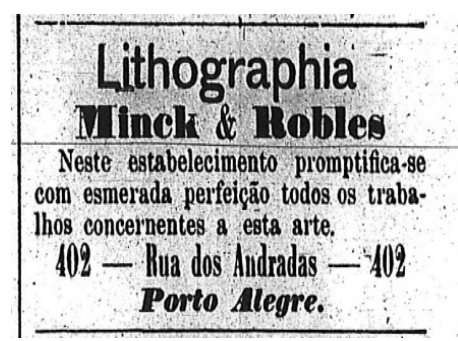

FONTE: O Exemplo, 29 maio 1904, p. 3.

FIGURA 4 - NOTA

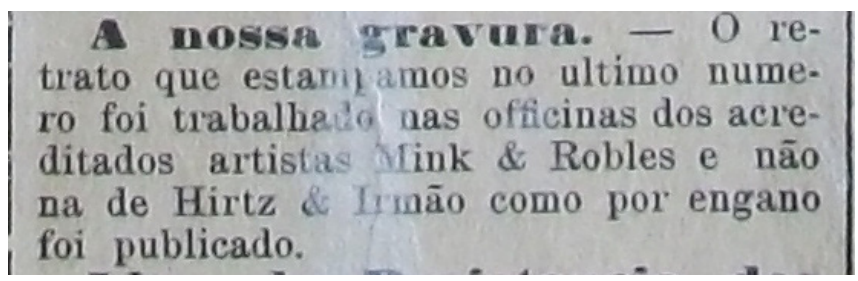

FONTE: O Exemplo, 13 maio 1904, p. 2. 
Segundo Marocco (2009), os irmãos Ferrari, que também se dedicaram ao retratismo, mais tarde mudaram o endereço do seu estúdio, que passou a chamar-se Ferrari \& Irmãos, para a Rua Duque de Caxias, $n^{\circ} 473$. Quanto a Lunara, Marroco afirma ter sido um fotógrafo amador que fotografou lugares mais simples e bucólicos nos arredores da cidade. Segundo a autora, "todos eles se notabilizaram por suas fotografias de negros". (MAROCCO, 2009, p. 166).

Inicio a análise com a homenagem prestada ao afrodescendente Octávio Feijó, de apenas 18 anos, homenageado no jornal $O$ Exemplo, por ocasião da conclusão de seu Curso de Modelagem Mecânica, no Instituto Técnico Profissional, de Porto Alegre. Reproduzo abaixo sua fotogravura:

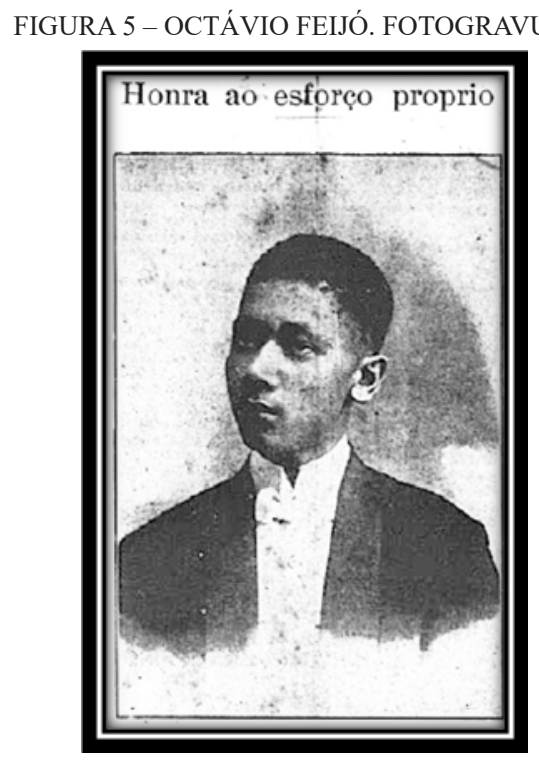

FONTE: Jornal O Exemplo, Porto Alegre, 21 jan. 1917, p. 1.

Outro elemento importante de uma reportagem de jornal é a escolha das manchetes e legendas das fotografias. De acordo com Roland Barthes (apud HALL, 1997), frequentemente é a manchete que faz a seleção dos vários significados possíveis da imagem e o ancora com palavras. O "significado" da fotografia existe então na conjunção da imagem e do texto. Também Helouise Costa (1992) chama atenção para a relação entre foto e legenda, descrevendo essa relação em três movimentos: "[...] inicialmente o olhar percorre a imagem, buscando uma inteligibilidade imediata, num segundo momento lê a legenda, buscando completar sua percepção primeira; por fim, retorna à imagem e con- 
clui a interpretação". (COSTA, 1992, p. 101). Do mesmo modo, Saraí Schmidt, analisando fotografias em jornais brasileiros, aponta que "[...] a legenda ensina aquilo que deve ser visto na fotografia publicada na imprensa, operando como um manual de instruções para leitura da imagem. (SCHMIDIT, 2006, p. 159). A autora apropria-se de Cauduro (1998), para afirmar que “[...] a representação verbal associada a uma representação visual quase sempre governa a cadeia de significados e o sentido que obtemos do conjunto". (CAUDURO, 1998, p. 86, apud SCHMIDIT, 2006, p. 159).

No caso da fotogravura de Octávio Feijó, a legenda "honra ao esforço próprio" parece marcar a importância que os redatores do Exemplo atribuíam ao esforço pessoal no enfrentamento das dificuldades de mobilidade e ascensão social da comunidade negra no início do século XX. O texto verbal da homenagem conclama os pais de família a instruírem seus filhos a seguirem o modelo de Octávio Feijó: "Mirem-se nesse exemplo todos aqueles que preferem não deixar os filhos sem instrução e sem ofício. É assim que vão se fazendo os futuros notáveis e grandes servidores da pátria, da família e da sociedade, nossos parabéns ao recém-formado! Honra ao esforço próprio!” (O Exemplo, 21 jan. 1917). Saliento, a partir da noção de endereçamento de Elizabeth Ellsworth, que a seleção da imagem de um jovem para essa homenagem melhor interpelaria o público de jovens negros, "sem instrução e sem ofício", para quem o apelo do "esforço próprio" estaria dirigido.

Hall (1997) destaca que os textos verbais e imagéticos ganham em significação quando são lidos considerando-se o contexto da época. Neste sentido, para entender-se o valor positivo atribuído à pátria nestes textos verbais é importante considerar que, a partir da Primeira Guerra Mundial, a emergência de um discurso nacionalista no Brasil ajudou a impulsionar a ideia da defesa da pátria. Os sentimentos nacionalistas ganharam completa expressão com a Semana de Arte Moderna de São Paulo, em 1922, em que intelectuais como Oswald de Andrade, Mário de Andrade e Tarsila do Amaral propuseram novas visões da cultura nacional. Micol Siegel (2009) e Paulina Alberto (2011) apontaram que os redatores da Imprensa Negra paulista estrategicamente apropriaram-se do discurso do nacionalismo e o associaram ao ideal de integração na nação, enquanto brasileiros que tinham direitos iguais aos dos brancos.

O Dr. Alcides Feijó das Chagas Carvalho, diretor do jornal O Exemplo entre 1916 e 1918, também foi homenageado pelos seus colegas redatores na ocasião em que deixava a direção do jornal. A imagem selecionada para representá-lo foi sua fotografia vestindo a toga da formatura na Escola Médico Cirúrgica, de Porto Alegre. O texto da homenagem salienta as "vicissitudes" e "dificuldades" enfrentadas ao longo de sua vida, que, no entanto, "[...] não lhe 
tiraram a energia, nem lhe arrefeceram a vontade firme de trabalhar e estudar". (O Exemplo, 04 fev. 1917). Reproduzo abaixo sua fotogravura:

FIGURA 6 - DR. ALCIDES FEIJÓ DAS CHAGAS CARVALHO. FOTOGRAVURA.

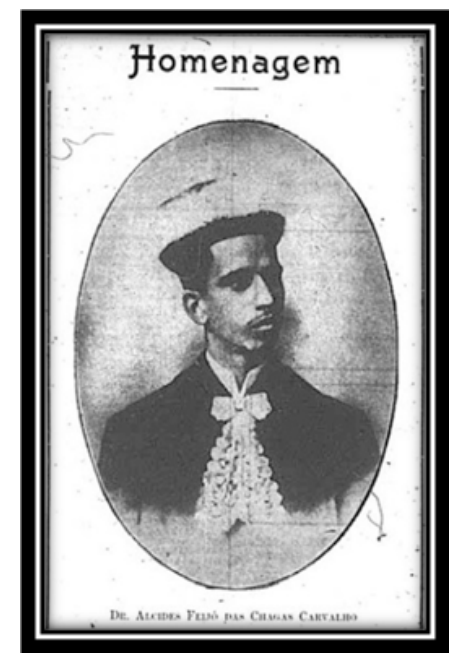

FONTE: Jornal O Exemplo, Porto Alegre, 04 fev. 1917, p. 1.

Chagas Carvalho foi representado como um "[...] espírito forte, aparelhado para as grandes lutas" e que "jamais descuidou os estudos" "sem alhear-se às atividades da imprensa nas poucas horas que lhe sobravam de descanso". ( $O$ Exemplo, 04 fev. 1917). Pedagogicamente, os redatores do jornal O Exemplo salientavam atributos considerados fundamentais para os jovens afrodescendentes triunfarem na sociedade brasileira: trabalhar e estudar, além de enfrentar com tenacidade as dificuldades que o contexto histórico da jovem república lhes reservava.

Também o jovem Dario de Bittencourt, diretor do jornal $O$ Exemplo na década de 1920, foi homenageado pelos seus colegas e representado com a toga, na ocasião da sua formatura no Curso de Direito da Escola de Ciências Jurídicas da Universidade Federal do Rio Grande do Sul. Na imagem selecionada para representar Dario de Bittencourt, mais uma vez, os redatores do jornal O Exemplo pedagogicamente subverteram a imagem estereotipada e negativa do negro sem cultura, pela representação positiva do afrodescendente culto e bem apresentado. No breve texto de sua homenagem salientaram seus "pertinazes esforços", representando-o como um exemplo de admirável tenacidade e "energitismo moral". (O Exemplo, 04 jan. 1925, p. 1). Reproduzo a seguir sua fotogravura: 
FIGURA 7 - DARIO DE BITTENCOURT. FOTOGRAVURA.

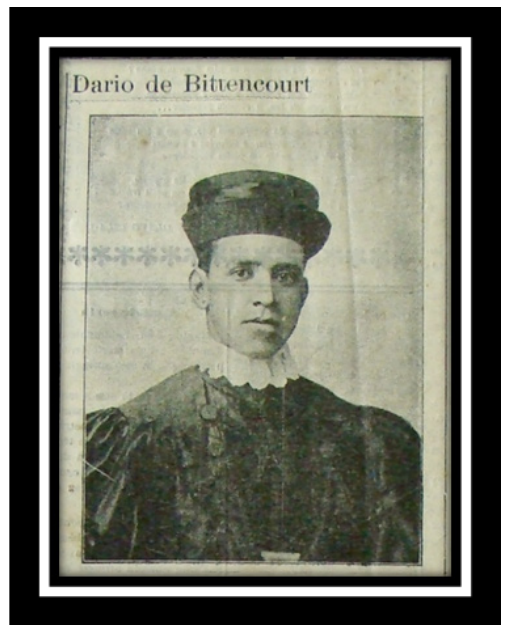

FONTE: Jornal O Exemplo, Porto Alegre, 04 jan. 1925, p. 1.

A estratégia pedagógica de produzir modelos de negros com os quais a comunidade negra de Porto Alegre pudesse se identificar e se inspirar na construção de suas subjetividades e identidades e de visibilizá-los no jornal por meio de fotogravuras vestindo a toga de formatura repetiu-se nas representações dos afrodescendentes Silva Dias e Arnaldo Dutra, que reproduzo a seguir:

FIGURA 8 - DR. SILVA DIAS. FOTOGRAVURA

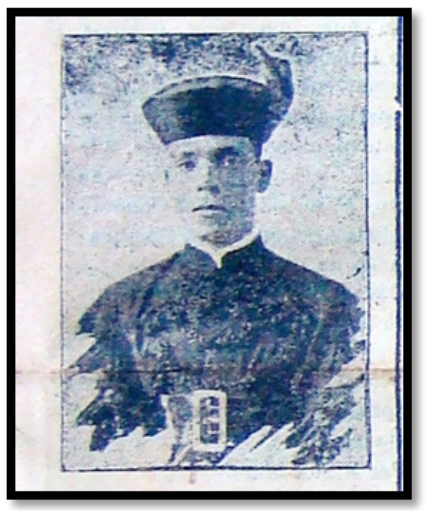

FONTE: Jornal O Exemplo, Porto Alegre, 05 maio 1925, p.1.
FIGURA 9 - DR. ARNALDO DUTRA. FOTOGRAVURA

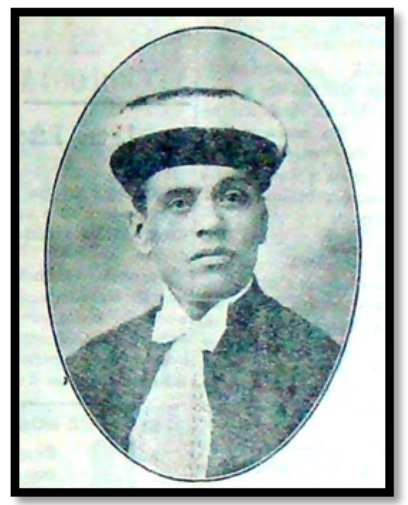

FONTE: Jornal O Exemplo Porto Alegre, 27 maio 1929, p.1. 
José da Silva Dias era um dos membros mantenedores do jornal $O$ Exemplo. O redator do jornal traçou seu perfil salientando seu alto grau de instrução, enfatizando sua vida acadêmica e acrescentando que, após concluir seus estudos secundários em Porto Alegre, recebeu o grau de bacharel na Faculdade de Ciências Jurídicas e Sociais em Brasília. Silva Dias foi representado como "batalhador", "grande espírito em contínuo e ascendente aperfeiçoamento", "grande inteligência", "caráter justiceiro e retilíneo" e admirado pela sua inteireza moral. Desta forma, os jornalistas negros mobilizavam e positivavam certos atributos como a moralidade, para construir um modelo ideal de negro.

É interessante observar, na direção apontada por Paula Sibilia (2012) para o ocidente no final do século XIX, que também no início do século XX reverberavam na Imprensa Negra as máximas da pedagogia kantiana do século XVIII: disciplinar, adestrar, civilizar e moralizar. (SIBILIA, 2012, p. 40). A moralização dos costumes da comunidade afrodescendente foi uma das principais bandeiras do jornal $O$ Exemplo nas primeiras décadas do século XX, em sintonia com a campanha de "saneamento moral" levada a cabo pelas elites políticas da época, visando a modernização da cidade de Porto Alegre. Esta linguagem moralizadora foi apropriada e negociada pelos jornalistas afrodescendentes em suas campanhas pela moralização dos costumes da comunidade negra, adaptando-a aos seus próprios sentidos de "melhoramento moral da raça".

Também as homenagens prestadas ao Dr. Arnaldo Dutra, ator, músico e médico, que foi redator-chefe do jornal O Exemplo a partir de 1927, destacavam suas qualidades morais e sua inteligência. Arnaldo Dutra foi representado como “[...] um filho amantíssimo, esposo fiel, irmão dedicado, nitidamente fortalecendo seus laços familiares". Seu caráter foi representado como exemplar, "[...] em que sobressaía a sua culta inteligência que punha a serviço das causas nobres" e seu "grande valor intelectual". (O Exemplo, 1927, p. 1).

Hall (1995), em sua discussão sobre codificação/decodificação, argumentou que uma das formas do receptor interpretar os textos da cultura dominante é negociando sentidos e atrelando-os aos seus próprios códigos de referência. Nesta direção, jornalistas afrodescendentes elaboraram diferentes leituras dos códigos hegemônicos em circulação na cultura da época. Assim, pode-se observar que laços familiares, relacionamentos sociais, força de vontade, trabalho e estudo foram marcadores pedagogicamente acionados nos textos verbais das homenagens prestadas pelos jornalistas afrodescendentes aos seus colegas de imprensa. No que se refere à ênfase nos laços sociais, pareciam se contrapor às representações de anomia social, frequentemente associadas à comunidade negra e que aparentemente explicavam o fracasso dos negros no pós-abolição. No que diz respeito às referências positivas atribuídas às famílias negras nos textos das homenagens, produzem significados que se contrapõem às repre- 
sentações estereotipadas que com frequência representaram os negros como incapazes de manter famílias.

Para finalizar, considero que as pedagogias disseminadas pelo jornal $O$ Exemplo, durante as homenagens prestadas aos afrodescendentes pelos seus colegas de imprensa, demonstraram o protagonismo desses intelectuais negros e oscilaram entre negociações de sentidos e transgressões simbólicas. Os jornalistas negros do jornal $O$ Exemplo tanto adaptaram os discursos dominantes aos seus próprios códigos culturais como os deslocaram e ultrapassaram, ampliando o repertório de representações de sujeitos negros, desnaturalizando lugares sociais cristalizados e afirmando, por meio de textos e imagens, outras formas de narrar o negro e de construir subjetividades e identidades negras positivas em Porto Alegre, já nas primeiras décadas do século XX.

\section{REFERÊNCIAS}

ALBERTO, P. Terms of Inclusion: Black Intellectuals in Twentieth-Century Brazil. Chapel Hill: The University of North Carolina Press, 2011.

ALBUQUERQUE, D. M. de. Pedagogia: a arte de erigir fronteiras. 2008. Disponível em: $<$ http:/cchla.ufrn.br/ppg/docentes/Durval/artigos/pedagogia_arte_de_erigir_fronteiras. pdf $>$. Acesso em: 15 maio 2015.

ARFUCH, L. O espaço biográfico: dilemas da subjetividade contemporânea. Rio de Janeiro: Eduerj, 2010.

AZEVEDO, D. A evolução técnica e as transformações gráficas em jornais brasileiros. Mediação, Belo Horizonte, v. 9, n. 9, p. 82-97, jul./dez. 2009.

BOHRER, F. R. A música na cadência da História: raça, classe e cultura em Porto Alegre no Pós-Abolição. Dissertação (Mestrado em História) - Instituto de Filosofia e Ciências Humanas da Universidade do Rio Grande do Sul, Porto Alegre, 2014.

BRUNO, F. Uma antropologia das "supervivências": as fotobiografias. In: SAMAIN, E. (Org.). Como pensam as imagens. Campinas: Editora da Unicamp, 2012. p. 91-106. BURKE, P. Testemunha ocular: história e imagem. Bauru: Edusc, 2004.

CAMOZATTO, V. C. Pedagogias do presente. Revista Educação \& Realidade. Porto Alegre, v. 39, n. 2, p. 573-593, abr./jun. 2014.

CAMOZZATO, V. C.; COSTA, M. V. Vontade de pedagogia - pluralização das pedagogias e condução de sujeitos. Cadernos de Educação da UFPel, n. 44, p. 22-44, jan/abr. 2013. 
COSTA, M. V. Prefácio: para além do bem e do mal. In: ABREU, B. F. de; ALMEIDA, T. S. de; ROCHA, C. M. F. (Org.). Mídia Impressa: para além do bem e do mal. Jundiaí: Paco Editorial, 2012.

COSTA, H. Aprenda a ver as coisas: fotojornalismo e modernidade na revista $\mathrm{O} C r u$ zeiro. Dissertação (Mestrado) - Escola de Comunicação e Artes, Universidade de São Paulo, São Paulo, 1992.

DOMINGUES, P. "O recinto sagrado": educação e antirracismo no Brasil. In: GOMES, F. dos S. e P. D. Da nitidez e invisibilidade: legados do pós-emancipação no Brasil. Belo Horizonte: Fino Traço, 2013. p. 269-304.

DUBOIS, P. O Ato Fotográfico. São Paulo: Papirus, 1994.

ELLSWORTH, E. Modos de endereçamento: uma coisa de cinema; uma coisa de educação também. In: SILVA, T. T. da (Org.). Nunca fomos humanos: nos rastros do sujeito. Belo Horizonte: Autêntica, 2001. p. 7-76.

FISCHER, R. M. B. O dispositivo pedagógico da mídia: modos de educar na (e pela) TV. Educação e Pesquisa, São Paulo, v. 28, n. 1, p. 151-162, jan./jun. 2002.

HALL, S. Encoding, decoding. In: DURING, S. (Ed.). The Cultural Studies Reader. London and New York: Routledge, 1995. p. 477-487.

HALL, S. The Spectacle of the 'Other'. In: HALL, S. Representation, cultural representations and signifying practices. London: Sage/Open University, 1997. p. 225-290.

HALL, S. Que "negro" é esse na cultura negra? In: SOVIK, L. (Org.). Da Diáspora: identidades e mediações culturais. Tradução de: RESENDE, A. La G. et al. Belo Horizonte: Editora UFMG; Brasília: UNESCO, 2003. p. 336-348.

MACHADO JÚNIOR, C. de S. Fotografias da vida social: identidades e visibilidades nas imagens publicadas na Revista do Globo (Rio Grande do Sul, década de 1930). 290 f. Tese (Doutorado em História) - Programa de Pós-Graduação em História, Universidade do Vale do Rio dos Sinos, São Leopoldo, 2011.

MACHADO JÚNIOR, C. de S. Fotografia, Imprensa de Variedades e Educação: Discursos Visuais e Textuais sob o Foco de uma Pedagogia de Revista. Hist. Educ. [On-line], Porto Alegre, v. 19, n. 47, p. 109-128, set./dez. 2015.

MARINHO, N. A Fotografia como fonte para a História da Educação: Um Olhar Sobre a Escola Profissional Feminina - Rio de Janeiro. Cadernos de História da Educação, v. 13, n. 2, p. 671-686, jul./dez. 2014.

MOROCCO, B. O cotidiano dos negros no exterior dos jornais de Porto Alegre: pistas de fotojornalismo no século XIX. Discursos Fotográficos, Londrina, v. 5, n. 5, p. 161$180,2009$.

MAUAD, A. M. Poses e flagrantes: ensaios sobre história e fotografias. Niterói: EdUFF, 2008. 
POSSAMAI, Z. R. A grafia dos corpos no espaço urbano: os escolares no álbum biografia duma cidade, Porto Alegre, 1940. Hist. Educ. [On-line], Porto Alegre, v. 19, n. 47, p. 129-148, set./dez. 2015.

SANTOS, I. Cultura teatral afrodescendente: representações raciais e pedagogias culturais no Teatro do Rio Grande do Sul. Tese (Doutorado em História) - Programa de Pós-Graduação em Educação, Universidade Federal do Rio Grande do Sul, Porto Alegre, 2015.

SEIGEL, M. Uneven encounters: making race and nation in Brazil and the United States. Durham and London: Duke University Press, 2009.

SIBILIA, P. Redes ou paredes. A escola em tempos de dispersão. Rio de Janeiro: Contraponto, 2012.

SCHMIDT, S. Professores e professoras nas lentes do jornal. In: COSTA, V. M. (Org.). O Magistério na política cultural. Canoas: Ed. Ulbra, 2006. p. 155-178.

Documentos consultados

JORNAL O EXEMPLO, Porto Alegre, 1892, 1904, 1917, 1925, 1927, 1929.

Texto recebido em 18 de outubro de 2015 . Texto aprovado em 27 de março de 2016. 
